PONTIFÍCIA UNIVERSIDADE CATÓLICA do RIO DE JANEIRO

Valoração de Empresa para Abertura de Capital

Ruderico Vasconcellos Alves Benites Gomes do Nascimento

Trabalho de Conclusão de Curso

Centro de CIÊnCIAS SOCIAIS - CCS

DePARTAMENTO de AdMINISTRAÇÃo

Graduação em Administração de Empresas 
Ruderico Vasconcellos Alves Benites Gomes do Nascimento

\section{Valoração de Empresa para Abertura de Capital}

Trabalho de Conclusão de Curso

Trabalho de Conclusão de Curso, apresentado ao programa de graduação em Administração da PUC-Rio como requisito parcial para a obtenção do titulo de graduação em Administração.

Orientador (a): Antonio Carlos Figueiredo

Rio de Janeiro

Maio de 2019. 


\section{Agradecimentos}

A minha mãe que sempre me incentivou e a qual, sem esse apoio não seria possível esse trabalho.

Aos meus queridos professores, Antonio Carlos Figueiredo, que me orientou nesse trabalho e teve paciência e compreensão com os percalços que tive. Ao Roberto Gil Uchôa que me acompanhou em parte da minha jornada profissional na área em que atuo hoje.

E, principalmente, gostaria de agradecer a minha família, ao meu atual chefe e a todos os profissionais da PUC - RJ que sempre me estenderam a mão e me ajudaram na minha jornada de crescimento e amadurecimento.

A todos meu mais sincero muito obrigado. 


\section{Resumo}

Nascimento, Ruderico Vasconcellos Alves Benites Gomes do. Valoração de Empresa para Abertura de Capital. Rio de Janeiro, 2019. Número de páginas p. Trabalho de Conclusão de Curso - Departamento de Administração. Pontifícia Universidade Católica do Rio de Janeiro.

As finanças de empresas têm avançado bastante no que se refere à análise de companhias convencionais, conhecidamente a grande valia que se evidencia no "valor" das organizações, seja para aplicá-las em casos de fusões, aquisições, orientação de desempenho dos gestores ou mais causas. No que diz

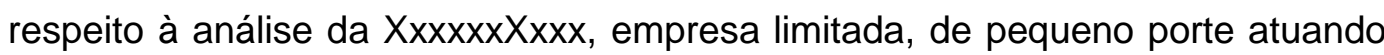
no seguimento de correlatos médicos, as formas convencionais de análise de companhias são aplicáveis mas a bibliografia corrente tanto de finanças como de contabilidade não abordam as peculiaridades do setor. A urgência de material científico e acadêmico que aborde a análise e percepção de instituições do setor é clara dada a grande importância estratégica econômica do setor, no entanto pouco explorada. A monografia apresentada procura permitir ao menos os primeiros passos para acertar a análise de companhias convencionais sob a ótica de valor para o setor a qual está inserida. A pesquisa apresenta as principais técnicas de análise de companhias, as peculiaridades do setor de correlatos médicos em comparação a companhias convencionais, o reconhecimento dos principais vetores de valor das indústrias comerciais e a asserção de um modelo de produção de movimento de caixa descontado para alcançar ao valor intrínseco. Após a manifestação desse modelo, ele foi refinado a testes em dados passados pela própria companhia para afirmar a sua aplicabilidade.

Palavras- chave
1. Finanças
2. Valuation
3. $X x x x x x X x x x$ 


\section{Abstract}

Nascimento, Ruderico Vasconcellos Alves Benites Gomes do. Valuation of Company for Capital Opening. Rio de Janeiro, 2019. Número de páginas p. Trabalho de Conclusão de Curso - Departamento de Administração. Pontifícia Universidade Católica do Rio de Janeiro.

Corporate finance has advanced a great deal in the analysis of conventional companies, known as the great value that is evidenced in the "value" of organizations, whether to apply them in cases of mergers, acquisitions, management orientation of performance or more causes. Regarding the analysis of $X x x x x x X x x x$, a small, limited liability company acting in the wake of medical correlates, conventional forms of company analysis are applicable, but the current literature on both finance and accounting does not address the peculiarities of the industry. The urgency of scientific and academic material that addresses the analysis and perception of sector institutions is clear given the great strategic economic importance of the sector, however little explored. The presented monograph seeks to allow at least the first steps to correct the analysis of conventional companies from the point of view of value for the sector to which it is inserted. The research presents the main analytical techniques of companies, the peculiarities of the medical correlates sector in comparison to conventional companies, the recognition of the main value vectors of the commercial industries and the assertion of a model of production of discounted cash movement to reach the intrinsic value. After demonstrating this model, it was refined to tests in data passed by the company itself to affirm its applicability.

Key-words
1. Finance
2. Valuation
3. $X x x x x x X x x x$ 


\section{Sumário}

1 Introdução 1

1.1. Introdução ao tema e ao problema do estudo 1

1.2. Objetivo do estudo 2

1.3. Objetivos intermediários do estudo 2

1.4. Delimitação do estudo 3

1.5. Justificativa e relevância do estudo 3

2 Contexto e realidade investigada 4

2.1. Definição de Valor 4

2.2. Tipos de Avaliação de Empresas 5

2.3. Métodos Tradicionais de Avaliação de Empresas - A escolha do Fluxo de Caixa Descontado (FCD) 5

2.4. O Método do Fluxo de Caixa Descontado (FCD) 6

2.4.1. Fluxo de Caixa Descontado (FDC) - Estruturação e Modelagem 7

2.5. O termômetro de Kanitz 13

3 Diagnóstico da situação problema e oportunidade 15

3.1. A indústria da Saúde 15

$\begin{array}{ll}\text { 3.1.1. O SUS } & 17\end{array}$

3.1.2. O Sistema Privado de Saúde 18

3.2. O Mercado de POINT-OF-CARE (POC) 19

4 Análise da situação e proposta de solução 22

4.1. A XxxxxxXxxx COMÉRCIO E INDÚSTRIA LTDA 22

4.2. Formação de Capital 25

4.2.1. FCFF (Free Cash Flow to the Firm) 27

$\begin{array}{ll}\text { 4.3. Perpetuidade } & 27\end{array}$

5 Conclusão - Valuation Pré e Pós Money 29

5.1. Índice de Solvência de Kanitz (1978) 30 


\section{Lista de Figuras}

Figura 1 - FÓRMULA ESTRUTURADA DO FCFE Erro! Indicador não definido.

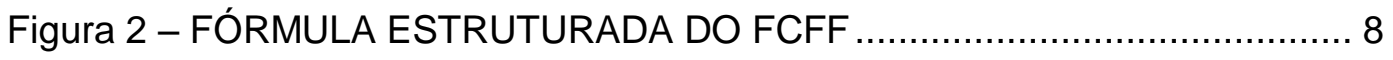

Figura 3 - FÓRMULA ESTRUTURADA DO WACC .................................... 9

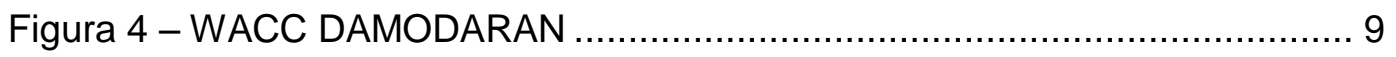

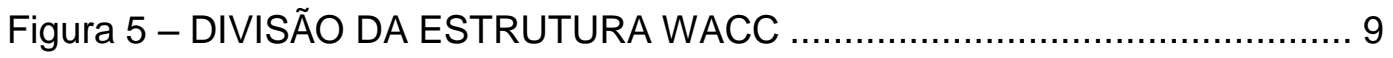

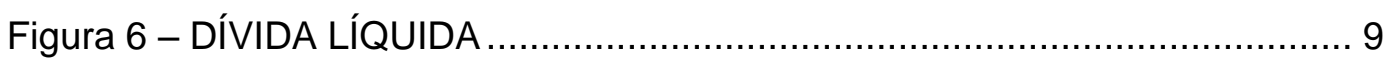

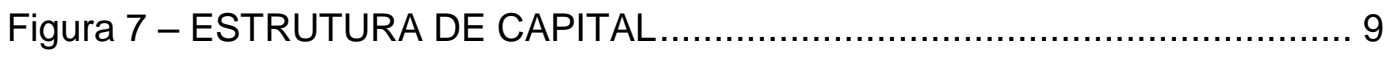

Figura 8 - FÓRMULA DA DDM......................................................... 11

Figura 9 - FÓRMULA DA DDM AJUSTADA ........................................... 12

Figura 10 -MACRO ESTRUTURA DE CAPITAL ..................................... 12

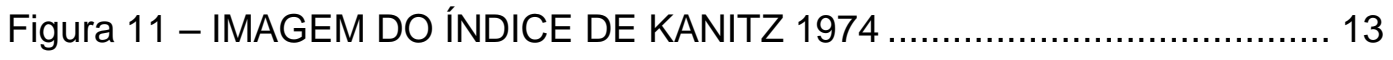

Figura 12 - GRÁFICO EXPECTATIVA DE VIDA - BRASIL .............................. 15

Figura 13 - GRÁFICO DE IDADE POPULAÇÃO - BRASIL ............................ 16

Figura 14 - GASTOS SAÚDE - BRASIL........................................... 17

Figura 15 - GASTOS GOVERNAMENTAIS COM SAÚDE - BRASIL ................ 18

Figura 16 - GASTOS SISTEMA PRIVADO DE SAÚDE - BRASIL ................... 18

Figura 17 - TAMANHO DE MERCADO POC TEST .................................... 20

Figura 18 - TAMANHO DO MERCADO DE POC - PRINCIPAIS SETORES .... 20

Figura 19 - ACERVO DA COMPANHIA LOCALIZAÇÃO ............................... 22

Figura 20 - ACERVO DA COMPANHIA PRODUÇÃO .................................. 22

Figura 21 - ACERVO DA COMPANHIA SELAGEM DE PRODUTOS .............. 22

Figura 23 - ACERVO DA COMPANHIA TRIAGEM CONVENCIONAL............. 23

Figura 24 - ACERVO DA COMPANHIA NOVA TRIAGEM ATRAVÉS DO USO DOS TESTES DE DIAGNÓSTICO RÁPIDO ........................................... 24

Figura 25 - TRABALHO DO AUTOR FORMAÇÃO DE CAPITAL ...................... 25

Figura 26 - TRABALHO DO AUTOR BETA DESALAVANCADO E RISCO DE MERCADO ........................................................................... 25

Figura 27 - DADOS DO SETOR http://pages.stern.nyu.edu/ adamodar/ ; DAMODARAN (2019) ....................................................................... 26 
Figura 28 - TRABALHO DO AUTOR “CUSTOS EXTRAORDINÁRIOS” ........... 27

Figura 29 - TRABALHO DO AUTOR FLUXO DE CAIXA LIVRE ....................... 27

Figura 30 - TRABALHO DO AUTOR VALUATION ESPERADO ...................... 29

Figura 31 - TRABALHO DO AUTOR FLUXO DE CAIXA E ESTIMATIVA DE

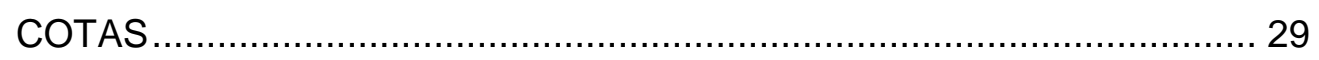

Figura 32 - TRABALHO DO AUTOR APLICAÇÃO DE KANITZ....................... 30 


\section{Introdução}

A presente Monografia é o Trabalho de Conclusão de Curso de Administração da Pontifícia Universidade Católica do Rio de Janeiro. O tema de pesquisa escolhido para a Monografia foi o da aplicação do Valuation, ou Avaliação de Empresas, para a empresa XXXXXXXXXX COMÉRCIO E INDÚSTRIA LTDA.

\subsection{Introdução ao tema e ao problema do estudo}

O termo Avaliação de Empresas provém da palavra em inglês Valuation, que significa valor desejado, ou, conferir valor. A gestão de valor tornou-se um ponto fundamental necessário para a administração financeira, sendo usada como recurso de controle, gratificação de administradores bem como também, em negociações para fusões e aquisições. Fundamento que, em última esfera, o propósito de toda entidade é potencializar o capital dos acionistas, os gestores que se concentrarem na produção de valor criarão companhias mais saudáveis que os que não o fizerem.

Dentre as principais situações que a Avaliação de Empresas possui colaboração crucial, podemos apontar as compras e vendas de negócios, fusões, cisões e incorporações de companhias, dissoluções de sociedades, liquidações de empreendimentos e análise da agilidade de gestores.

Há inúmeras formas de realizar a Avaliação de Empresas, no entanto, na atual composição, o método do Fluxo de Caixa Descontado foi empregado como padrão.

Sendo assim, a avaliação de valor de uma estabelecimento é composta fundamentalmente por três fases: Projeção do fluxo de caixa futuro da empresa, a determinação da taxa de desconto para o fluxo de caixa projetado e o cálculo do valor presente do fluxo de caixa pela taxa de desconto definida. 


\subsection{Objetivo do estudo}

Este trabalho tem o objetivo de apresentar a valoração estratégica da empresa XXXXXXXXXX COMÉRCIO E INDÚSTRIA LTDA dando fundamento e tendo como base a viabilidade econômica - financeiro da organização sobre o provável valor justo das ações de emissão da $X x x x x x X x x x$, se baseando nas Demonstrações Financeiras com data-base de 31 de dezembro de 2018. As projeções operacionais levando em consideração o seu mix de produtos atuais com respectivas estatísticas de vendas nos últimos 12 meses para captação de recursos a serem obtidos com terceiros. O estudo de valor foi baseado na metodologia do Fluxo de Caixa Descontado (FCD). O Objetivo é de apresentar à XxxxxxXxxx resultados parciais da avaliação em curso.

Adicionalmente, a estimativa de valor justo dos cenários expostos nesse Relatório não deve ser considerada como um conselho/recomendação de investimento, "fairness opinion" ou utilizado para financiamento/captação de recursos, bem como qualquer outra finalidade, exceto uso acadêmico.

É importante destacar que não foi investigado de forma independente, bem como não foi aplicado nenhum processo de auditoria nas informações fornecidas. Adicionalmente, nossas recomendações e cálculos apresentados são baseados em expectativas mercadológicas da indústria, bem como nas condições macroeconômicas existentes na data-base do trabalho, as quais poderão ser diferentes no futuro e, consequentemente, impactar a operação da $\mathrm{X} x \mathrm{xx} x \mathrm{X} X \mathrm{xxx}$.

$E$ de largo entendimento e fundamental enfatizar que, em uma decisão de investimento é preciso avaliar vários elementos, no entanto, podemos enfatizar dois componentes. O retorno previsto e o risco assumido inerente, esse binômio compreende o estaca principal das finanças (Indefinição de Projeção, Volatilidade dos Fluxos de Caixa, Risco de Taxa de Juros, Risco de Mercado), precisam ser consideradas em todo estudo a fim de entregar o melhor resultado fidedigno realizável.

\subsection{Objetivos intermediários do estudo}

Para a obtenção do resultado esperado foram adotadas as seguintes premissas a fim de atingir o objetivo desejado.

- Dados contábeis extraídos dos balanços patrimonial fornecidos pela companhia. 
- Weighted Average Cost of Capital (WACC) para calcular o custo médio ponderado de capital.

- O Capital Asset Pricing Model (CAPM) para server de base para 0 modelo de precificação de capital.

- A aplicação do termômetro de Kanitz para medir o grau de solvência ou insolvência da empresa.

E, finalmente, realizar o fluxo de caixa projetado para os próximos 05 anos da empresa.

\subsection{Delimitação do estudo}

O presente estudo visa levantar uma projeção de caixa para os próximos 05 anos com base apenas nos dados contábeis da XXXXXXXXXX COMERCIO E INDÚSTRIA LTDA do estado do Rio de Janeiro.

\subsection{Justificativa e relevância do estudo}

O presente estudo visa agregar valor a tomadas de decisões financeiras para a abertura de capital e aquisição de participação na empresa além de trazer maior confiança e aceitabilidade quanto ao valor estimado da empresa para um período futuro.

Visa também à aplicação de conceitos acadêmicos na elaboração deste trabalho mostrando de forma prática, aplicações teóricas adquiridas na instituição de ensino. 


\section{Contexto e realidade investigada}

Serão apresentados, no referencial teórico, conceitos para a compreensão do valuation e sua aplicação. Os conceitos apresentados são o do Valor do ponto de vista da organização, Avaliação de Empresas e seus principais métodos, um detalhamento do método do Fluxo de Caixa Descontado, bem como seus modelos de aplicação.

\subsection{Definição de Valor}

Para Ferreira (1988, p. 663), valor pode ter incontáveis significados, dentre eles: O similar em quantia ou propriedades de algo; Padrão pelo qual dado indivíduo ou coisa é estimável em maior ou menor nível, virtude ou mérito intrínseco; bem como maior ou menor admiração que certa pessoa tenha por certo bem ou serviço, podendo ser este de utilização ou de troca.

Segundo Póvoa (2007, p. 13), o valor legal de certa instituição para os seus donos é o que ela pode conceber de retorno no futuro expresso em valores no presente. Onde são necessários três passos para chegar a esse valor: Projetar o fluxo de caixa da empresa, fixar uma taxa de desconto (Custo de oportunidade) e trazer o fluxo a valor presente pela taxa de desconto.

Para Assaf Neto (2008, p. 177), uma empresa é geradora de valor no momento em que remunera seus acionistas acima de suas perspectivas, ou seja, no momento em que os proventos do negócio superam a taxa de retorno exigida pelos donos do capital injetado no estabelecimento.

Ainda segundo Assaf Neto (2008, p. 432), no ambiente das finanças corporativas, o propósito está na maximização do valor de mercado da instituição. A qualidade das decisões é definitiva para o patrimônio e essas decisões precisam ser tomadas com base na correlação de risco e resultado esperados. Então, a performance operacional da empresa precisa ser classificado pelo valor econômico originado, de forma coerente com o propósito da maximização da patrimônio de seus acionistas.

De acordo com Damondaran (1994, p. 1), a noção de que investidores não compram um ativo por mais do que ele de fato vale parece óbvia, porém isso é 
observado constantemente no mercado. O pretexto de que o valor está nos olhos de quem adquire é absurda, já que as percepções de valor precisam ter amparo na realidade.

\subsection{Tipos de Avaliação de Empresas}

Para Damodaran (1997, p. 5), o objetivo da Avaliação de empresas depende do propósito que se possui ao avaliar uma empresa. Os principais motivadores de sua aplicação são a análise e administração de carteiras de ações, avaliação para aquisições de instituições e avaliações nas finanças corporativas. Então, a avaliação de empresas nas análises e controle de carteiras de ações, é realizada com o intuito de identificar possibilidades em negócios que estejam ou subavaliados ou superavaliados.

No caso de aquisições, o adquirente precisa realizar a avaliação de um valor procedente em que esteja pronto a pagar e o vendedor precisa alcançar a um valor justo em que esteja disposto vender a empresa. No caso das finanças corporativas, uma ótima maneira de ver as decisões gerenciais é a partir do valor da empresa, já que qualquer negócio adequadamente gerenciado constantemente agrega valor. Então, o papel da avaliação de empresas nas áreas financeiras é de forte legitimidade e prestígio no meio financeiro.

Para Erich A. Helfert (2000, p. 278), pode-se conceitua oito usos comuns do termo valor, quando aplicado a empresas, contudo, o presente focará em Avaliação por fluxos de caixa descontado (FCD) que, ainda para Erich (2000, p. 278), significa o valor do ativo pelo valor dos fluxos de caixa futuros esperados.

\subsection{Métodos Tradicionais de Avaliação de Empresas - A escolha do Fluxo de Caixa Descontado (FCD)}

Há variadas metodologias de Avaliação de Empresas. Serão descritas abaixo os principais processos da bibliografia e observando que há vários modelos de avaliação de empresas, a escolha precisa observar o objetivo da análise e as qualidades próprias do empreendimento. Esses modelos são geralmente classificados em técnicas comparativas de mercado, técnicas baseadas em ativos e passivos ajustados, e técnicas baseadas no desconto de fluxos futuros de vantagens. 
Também considerando Celso Funcia Lemme (2004, p. 29) "A essência do método é associar o valor de uma empresa ao valor-presente dos seus fluxos de caixa futuros, separando o fluxo de caixa operacional dos fluxos extraordinários e agrupando os componentes do fluxo de caixa de acordo com seus níveis de risco. Embora aplicável a grande número de situações, o método, por lidar com projeções e ter foco temporal no futuro, pode envolver grande dose de arbitrariedade.". Isto evidência que, a estratégia pondera com atenção o resultado do capital no período, o qual pode ser subordinado a uma grande diversidade de decisões, permitindo maior racionalidade nas tomas de decisão da alta gerência e mesa diretora se valendo do ponto de vista financeiro de caixa e não contábil.

Dessa maneira, podemos deduzir que a bibliografia utilizada e os analistas de mercado concebem inclinação pelo uso do princípio do Fluxo de Caixa Descontado para avaliar companhias e são motivados, especialmente, pelos princípios da matemática financeira que levam em atenção o valor do capital no período. Uma corporação é um ativo formador de fluxos de caixa e seu preço, então, precisa demonstrar o valor existente dos fluxos futuros, trazidos a uma taxa que represente o custo de oportunidade da empresa ou de seus acionistas.

\subsection{O Método do Fluxo de Caixa Descontado (FCD)}

Para Damodaran (1999, Cap. 2), há três modelos de categorizar fluxos de caixa. O primeiro é através de fluxos de caixa para a empresa, que imaginam quaisquer ganhos de capital da instituição e fluxos destinados aos acionistas. Os fluxos para acionistas englobam também os fluxos de dividendos ou os Fluxos de Caixa Livres para os Acionistas. A segunda maneira de categorizar é com os fluxos nominais ou reais. Os fluxos nominais incorporam a inflação esperada e dessa forma precisam ser representados em espécie própria (ex.: reais, ienes ou dólares americanos, etc.). Os fluxos reais não contemplam a inflação e verificam somente as variações no algarismo de unidades vendidas e quantidade tangível de precificação. O terceiro e último método de categorizar os fluxos, é se eles são considerados antes dos impostos ou após a incidência deles. A maneira mais corriqueira é a após os impostos. Na hipótese de que sejam usados os fluxos após os impostos, seria preciso adaptar um aditivo na taxa de desconto do fluxo para adaptar o resultado do efeito dos impostos. 


\subsubsection{Fluxo de Caixa Descontado (FDC) - Estruturação e Modelagem}

O Fluxo de Caixa Livre para o Acionista (FCFE = Free Cash Flow to Equity) é a analise da empresa pela ótica do investidor. Neste caso a estruturação dos fluxos de caixa devem conter todos os financiamentos.

A estruturação do FCFE é a seguinte:

+ Lucro Líquido

+ Depreciação

- Investimentos

- Variação de Capital de Giro

+ Captação de Recursos de Terceiros (Financiamentos)

- Amortização das Parcelas do Principal dos Financiamentos

$$
=\text { FCFE }
$$

No caso do FCFE os fluxos devem ser descontados pelo custo do capital próprio do investidor (empresa ou acionista) Ke, determinado mais comumente pelo CAPM.

A formula para determinação do valor da empresa pela ótica do acionista é a seguinte:

$$
V_{F C F E}=\sum_{t=0}^{n} \frac{F C F E_{t}}{\left(1+k_{e}\right)^{t}}
$$

Figura 1 - FÓRMULA

\section{ESTRUTURADA DO FCFE}

Onde:

VFCFE - valor presente da empresa para o acionista

FCFE - fluxo de caixa livre para o acionista

$\mathrm{Ke}$ - custo do capital próprio

$\mathrm{t}$ - período do fluxo de caixa previsto 
O Fluxo de Caixa Livre para a Empresa (FCFF = Free Cash Flow to Firm) é a analise da empresa pela ótica da empresa como capacidade própria, sem considerar os endividamentos.

A estruturação dos FCFF é a seguinte:

+ EBIT (1 - Alíquota de Imposto de Renda) = NOPAT

+ Depreciação

- Investimentos

- Variação de Capital de Giro

$=\mathrm{FCFF}$

$\mathrm{OU}$

+ FCFE

+ Juros (1 - Alíquota de Imposto de Renda)

- Captação de Recursos de Terceiros (Financiamentos)

+ Amortização das Parcelas do Principal dos Financiamentos

$=$ FCFF

No caso do FCFF os fluxos devem ser descontados pelo custo do médio ponderado de capital apresentado a seguir.

A formula para determinação do valor da empresa pela ótica da geração de valor é a seguinte:

$$
V=\sum_{t=0}^{n} \frac{F C F F_{t}}{(1+W A C C)^{t}}
$$

Figura 2 - FÓRMULA

\section{ESTRUTURADA DO FCFF}

Onde:

$\mathrm{V}$ - valor presente da empresa

FCFF - fluxo de caixa livre para a empresa

WACC - custo médio ponderado de capital

$\mathrm{t}$ - período do fluxo de caixa previsto 
Já o custo médio ponderado de capital (WACC) é dado pela seguinte expressão.

$W A C C=\%_{e} \times K_{e}+\%_{d} \times K_{d} \times(1-T)$

Figura 3 - FÓRMULA ESTRUTURADA DO WACC

\%e - percentual de capital próprio

$\mathrm{Ke}$ - Custo do Capital Próprio

$\% d$ - percentual de dívida

Kd - Custo do Dívida

T - Alíquota de Imposto de Renda

Segundo Damodaran (1999, p. 251), o Custo Médio Ponderado de Capital (Weighted Average Cost of Capital - WACC) é a média ponderada dos custos dos diversos componentes de financiamento utilizados por uma empresa, incluindo dívida, patrimônio líquido e títulos híbridos. Também devem ser considerados benefícios fiscais e riscos adicionais. O custo médio ponderado de capital (WACC) pode ser também explicado pela figura abaixo:

$$
W A C C=\left(\frac{E}{D+E}\right) \times K_{e}+\left(\frac{D}{D+E}\right) \times K_{d} \times(1-T)
$$

Figura 4 - WACC DAMODARAN

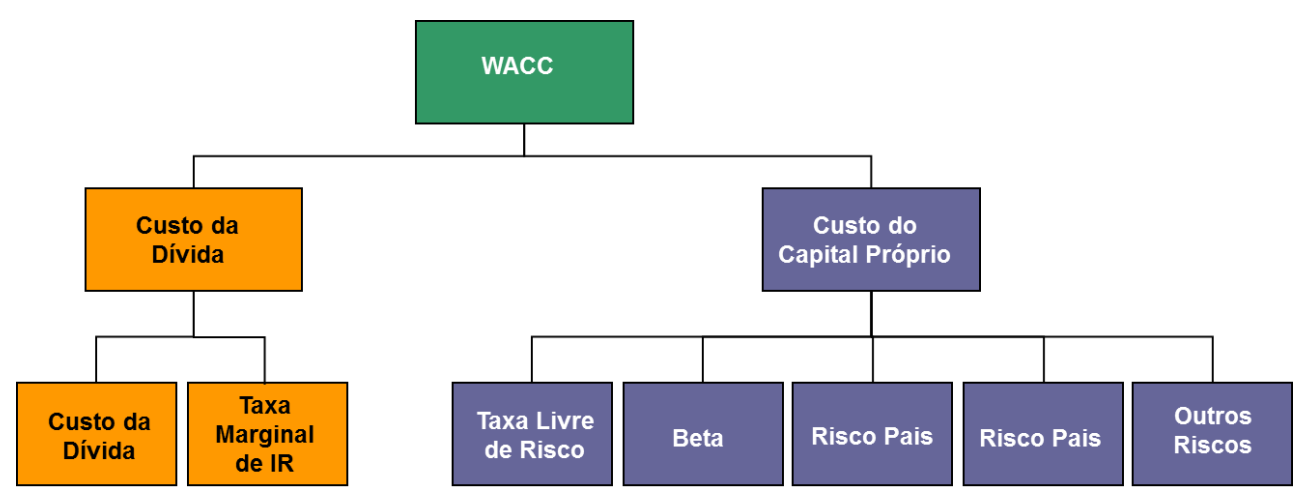

Figura 5 - DIVISÃO DA ESTRUTURA WACC

$$
K_{e}=R_{f}+\beta\left(R_{m}-R_{f}\right)+R_{\text {Pais }}+R_{\text {Outros }} \quad K_{\text {dliq }}=K_{d}+(1-T)
$$


Nas duas abordagens o importante é perceber que as utilizações de taxas de descontos não compatíveis com a análise podem distorcer os valores da avaliação. Por isso a escolha por um método ou outro de analise de investimentos acorre devido aos seguintes para argumentos:

Casos quando se deve utilizar o FCFE:

- Quando o endividamento da empresa é estável, podendo ser alto ou baixo;

- Quando se avalia o Capital Próprio ou Ações.

Casos quando se deve utilizar o FCFF:

- Quando a empresa tem um endividamento oscilante, e pretende alterar o endividamento ao longo do tempo.

- Quando a Aquisição excluir questões de endividamento.

- Quando o valor da dívida é maior que o valor do Capital próprio.

O "capital asset pricing model (CAPM)" foi desenvolvido por William Sharpe.

O CAPM (Capital Asset Pricing Model) define o custo de capital do acionista ou investidor, de acordo com Povoa (2007, Cap. 5) existem duas possíveis taxas de desconto. O Capital Asset Pricing Model (CAPM) e o Custo Médio Ponderado de Capital (Weighted Average Cost of Capital - WACC). O primeiro se aplica, quando o fluxo de caixa projetado for ao acionista, ou seja, os lucros após as despesas financeiras. O segundo se aplica quando o fluxo de caixa de referência for o Lucro Operacional.

O cálculo do CAPM assume quatro hipóteses: A inexistência de custos de transação, total liquidez de compra e venda nos mercados, simetria de informações no mercado e a possibilidade de eliminar o risco de um portfólio por meio da diversificação. A fórmula do CAPM é a seguinte:

$\mathrm{Ke}=\mathrm{Rf}+\mathrm{b}(\mathrm{Rm}-\mathrm{Rf})$

Sendo:

$\mathrm{Ke}=$ Custo do Capital Próprio

$\mathrm{Rf}=$ Rentabilidade do ativo livre de risco

$\mathrm{Rm}=$ Rentabilidade do ativo de mercado

$b=$ Beta (representa a relação do risco do ativo em relação ao mercado). 
O CAPM é a expectativa de retorno do acionista com base em uma taxa livre de risco, como as praticadas por títulos do governo, e um prêmio de risco do investimento.

A perpetuidade é o momento em que uma empresa atinge o seu potencial máximo de produtividade, em outras palavras, a mesma manterá em níveis estáveis suas receitas, custos e estrutura de capital. Nesse estado, dizemos que a empresa atingiu o estágio de maturidade.

Duas formas de calcular a taxa de perpetuidade. A primeira é a perpetuidade sem crescimento do fluxo de caixa e a segunda é a perpetuidade com crescimento do fluxo de caixa. O cálculo da primeira é obtido pela razão do Fluxo de caixa projetado pela taxa de desconto projetado. O cálculo da segunda é a razão do fluxo de caixa projetado pela diferença entre a taxa de desconto e a taxa de crescimento projetada.

Aplicaremos aqui o conceito de Damodaran (1996, Cap.13) sobre o modelo de crescimento de Gordon que considera uma taxa de crescimento constante no valor dos pagamentos de dividendos no infinito. Esse modelo deveria ser aplicado a empresas que apresentam um crescimento estável e o Modelo de Desconto de Dividendos (Discounted Dividend Model - DDM) que, também para Damodaran (1996, Cap.13), é o modelo mais antigo e o melhor método a ser aplicado na análise por Fluxo de Caixa Descontado. A ideia por trás do DDM é a de que um investidor observa dois tipos de fluxos ao avaliar um ativo, os dividendos que receberá e o preço de venda do ativo no final do período previsto e considerando que o preço do ativo no final do período.

Assim temos as fórmulas:

DDM

$$
\text { Valor por ação }=\sum_{i=1}^{t=\infty} \frac{E\left(D P S_{t}\right)}{\left(1+k_{e}\right)^{t}}
$$

\section{Figura 8 - FÓRMULA DA DDM}

Onde:

DPSt $=$ Valor da expectativa de dividendos por ação, considerando que os

Dividendos têm valores constantes.

$\mathrm{Ke}=$ Custo de oportunidade da ação 
DDM ajustado por Gordon

\section{Valor da ação $=\frac{D P S_{1}}{K e-g}$}

\section{Figura 9 - FÓRMULA DA DDM AJUSTADA}

Onde:

DPS1 = Dividendo esperado para o próximo ano

$\mathrm{Ke}=\mathrm{Taxa}$ de retorno exigida pelo investidor

$\mathrm{g}=$ Taxa de crescimento dos dividendos até o infinito

Algumas ressalvas feitas: A primeira é que a estimativa da taxa de crescimento dos dividendos deve ser igual à estimativa da taxa de crescimento dos lucros da empresa, pois caso contrário, no longo prazo, o valor a ser pago nos dividendos seria maior do que o próprio lucro. O segundo ponto é que a taxa de crescimento da empresa não poder ser superior à economia em que ela atua, pois caso contrário, ela se tornaria maior que a própria economia, na visão de longo prazo. Por fim temos o seguinte macro estrutura:

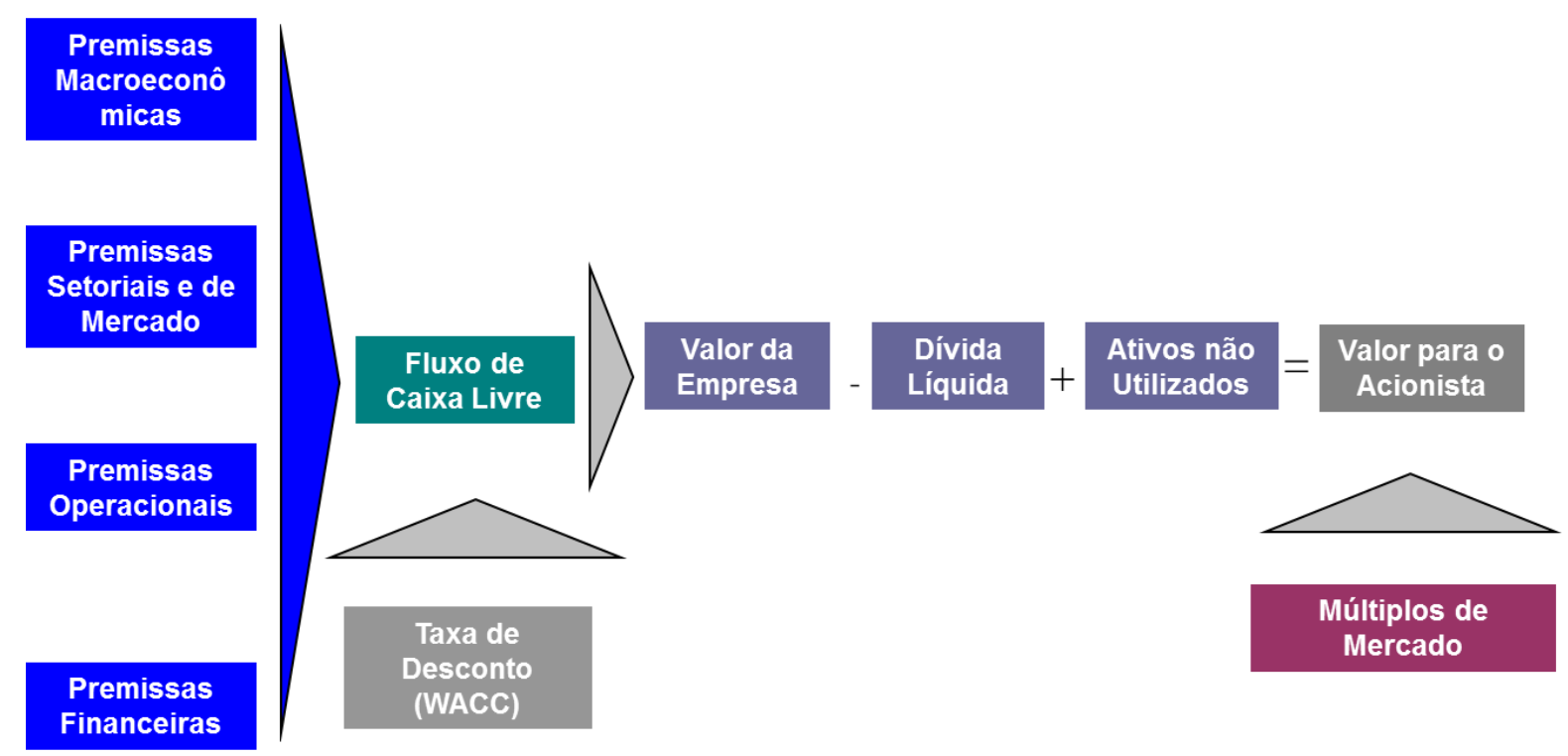

Figura 10 -MACRO ESTRUTURA DE CAPITAL 


\subsection{O termômetro de Kanitz}

A fim de conferir maior acuracidade e corroborar a análise da XxxxxxXxxx e, dado que a fonte trata-se do Balanço fechado de 2018, realizaremos a aplicação do índice de solvência de Kanitz.

Em 1974, Stephen Charles Kanitz publicou um artigo intitulado "COMO PREVER FALÊNCIAS DE EMPRESAS" REVISTA NEGÓCIOS EM EXAME Dezembro 1974 nas Páginas 95 a 102. No artigo em questão, Kanitz apresenta suas conclusões sobre um estudo que realizou analisando aproximadamente 5.000 demonstrações contábeis de empresas brasileiras. Após, ele escolheu aleatoriamente 21 empresas, que haviam falido entre 1972 e 1974, e analisou os balanços referentes aos dois anos anteriores a falência.

E dito, em seu artigo que "Os sintomas de que uma empresa está a caminho da falência ou concordata podem ser notados muito antes que ocorra o desenlace".

Nele é publicada também a seguinte imagem abaixo:

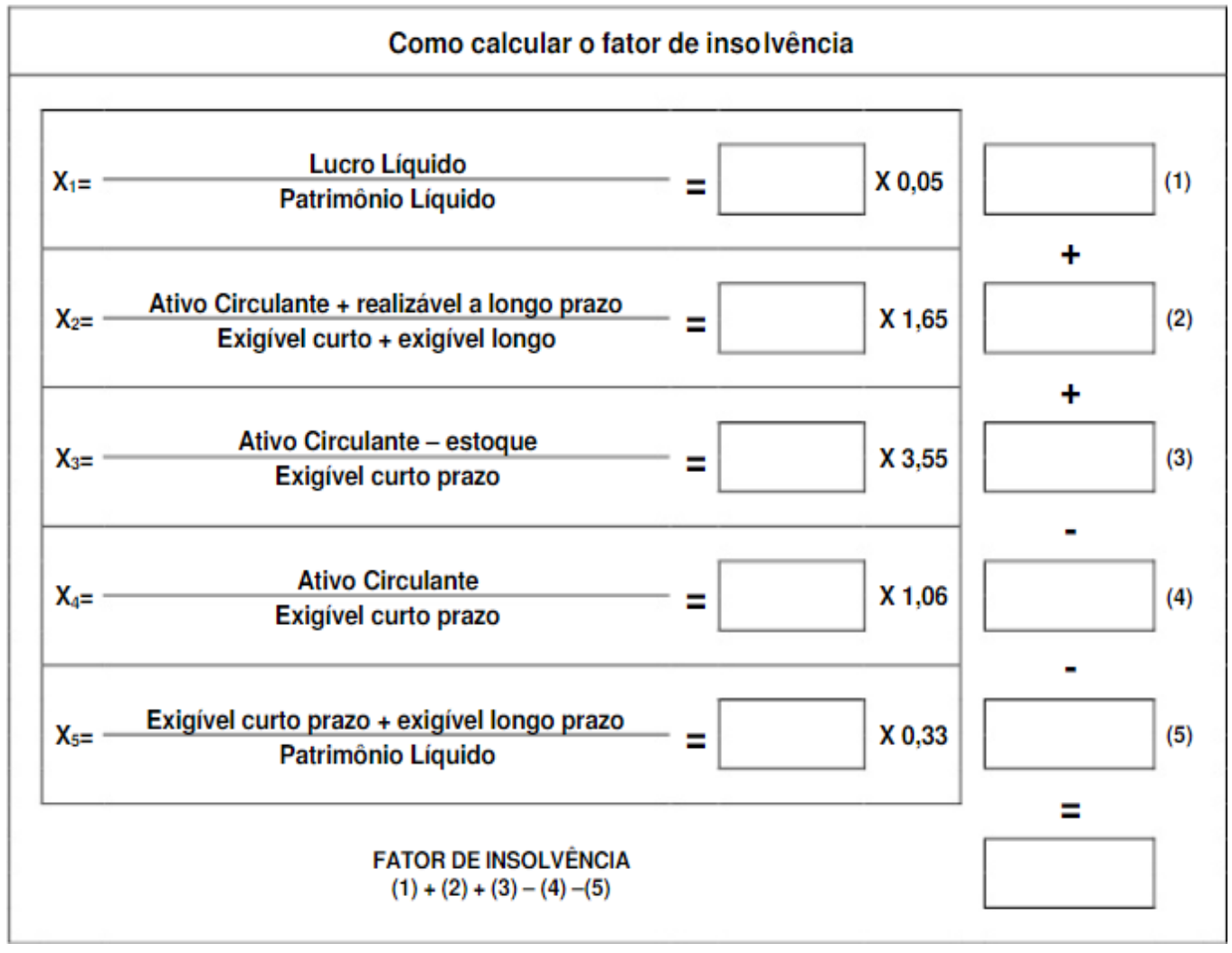

Figura 11 - IMAGEM DO ÍNDICE DE KANITZ 1974 
O mesmo pode ser reescrito como abaixo:

$\mathrm{Y}=0,65 \times \mathrm{ROE}+1,65 \times \mathrm{LG}+3,55 \times \mathrm{LS}-(1,06 \times \mathrm{LC}+0,33 \times \mathrm{GE})$

Onde: $\mathrm{ROE}=\mathrm{LL} / \mathrm{PL}$

$$
\begin{aligned}
& \mathrm{LG}=\mathrm{AL} / \mathrm{PE} \\
& \mathrm{LS}=(\mathrm{AC}-\mathrm{E}) / \mathrm{PC} \\
& \mathrm{LC}=\mathrm{AC} / \mathrm{PC} \\
& \mathrm{GE}=\mathrm{PE} / \mathrm{PL}
\end{aligned}
$$

Como: Acima de 7:

Tranquilo

$\begin{array}{ll}\text { Entre } 0 \text { e 7: } & \text { Solvente } \\ \text { Entre - } 3 \text { e 0: } & \text { Penumbra }\end{array}$

Abaixo de -3: $\quad$ Provável insolvência

O termômetro como ferramenta matemática de caráter estatístico, poderia refletir a situação financeira da empresa, determinando a tendência de uma empresa falir ou não.

Vale destacar aqui que, o modelo Kanitz deriva de uma ponderação estatística de cinco índices, porém, segundo Kassai e Kassai (1998), apud Andrade (2004), e "os coeficientes atribuídos a cada indicador são resultado do tratamento estatístico dado pelo autor e não foram revelados em seu artigo".

Com dito, a fim de complementar o presente estudo, o mesmo será aplicado como mais um fator decisório sobre a aplicação de capital na

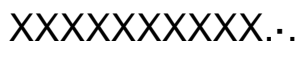




\section{Diagnóstico da situação problema e oportunidade}

Com uma população total de aproximadamente 200 milhões de habitantes, com crescimento populacional de $0,7 \%$ ao ano (média dos países da OCDE é de 0,4\% ao ano), o Brasil é considerado um dos maiores mercados mundiais de produtos e serviços relacionados ao mercado de saúde. Porém é preciso analisar um pouco mais a fundo certas características geográficas e sociais da população para entender melhor o contexto ao qual a $\mathbf{X x x} \mathbf{x x} \mathbf{X} \mathbf{x x x}$, que será apresentada mais afrente no capítulo 4 , está inserido e o verdadeiro potencial deste vasto mercado.

\subsection{A indústria da Saúde}

De acordo com estatísticas do Banco Mundial, o Brasil vem apresentando continuamente um aumento na expectativa de vida de seus habitantes, alcançando a marca de 74 anos conforme tabela abaixo.

\section{Expectativa de Vida (anos) - Brasil}

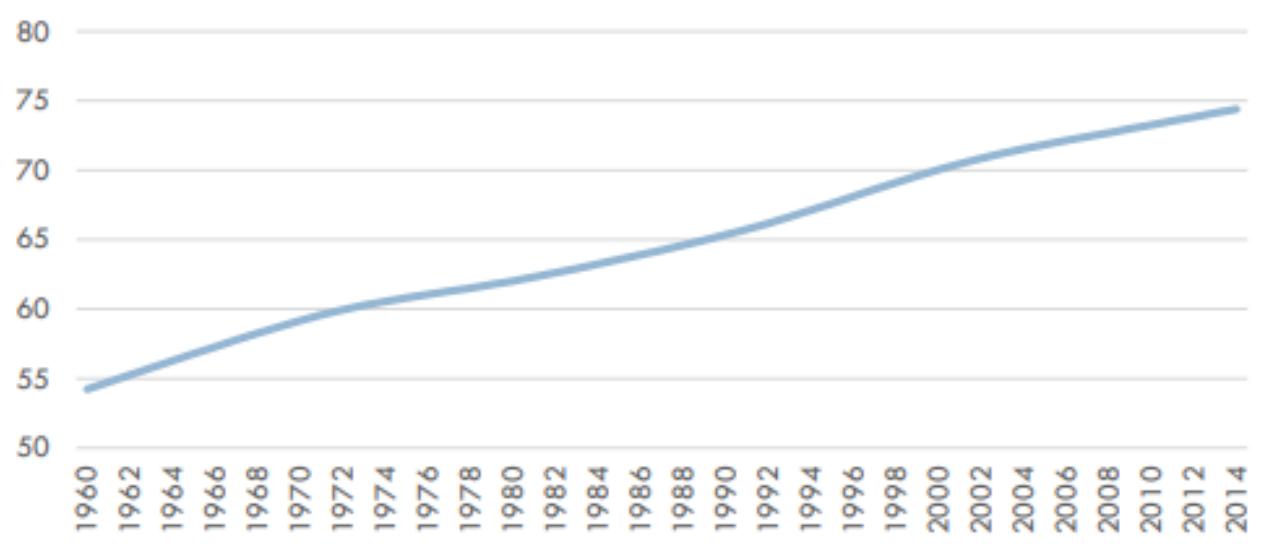

Figura 12 - GRÁFICO EXPECTATIVA DE VIDA - BRASIL

Apesar desses contínuos aumentos, essa expectativa de vida ainda é consideravelmente baixa em relação à dos países da $\operatorname{OCDE}(80,4$ anos), o que em conjunto com a evolução dos tratamentos de saúde irá aumentar ainda mais a expectativa de vida do brasileiro nos próximos anos. 
O aumento da expectativa de vida dos brasileiros nos últimos anos, em conjunto com a considerável diminuição das estatísticas de mortalidade infantil (entre 1990 e 2014 baixou de mais de 50 mortes a cada 1000 nascimentos para menos de 20), vem causando o "envelhecimento" da população brasileira.

Apesar de ainda ser considerado um país de jovens, com a idade mediana da população em 30 anos, é possível observar o envelhecimento da população por meio do "Aging Index", estatística do Banco Mundial que consiste no número de pessoas com mais de 60 anos para cada 100 jovens abaixo dos 15 anos. Entre 2000 e 2012 esse número subiu 50\%, de 30 para 45.

Este processo de "envelhecimento" que a população brasileira vem passando e continuará passando nas próximas décadas vem alterando de forma relevante a distribuição da população por faixa etária, também conhecida como pirâmide etária, conforme mostrado abaixo:

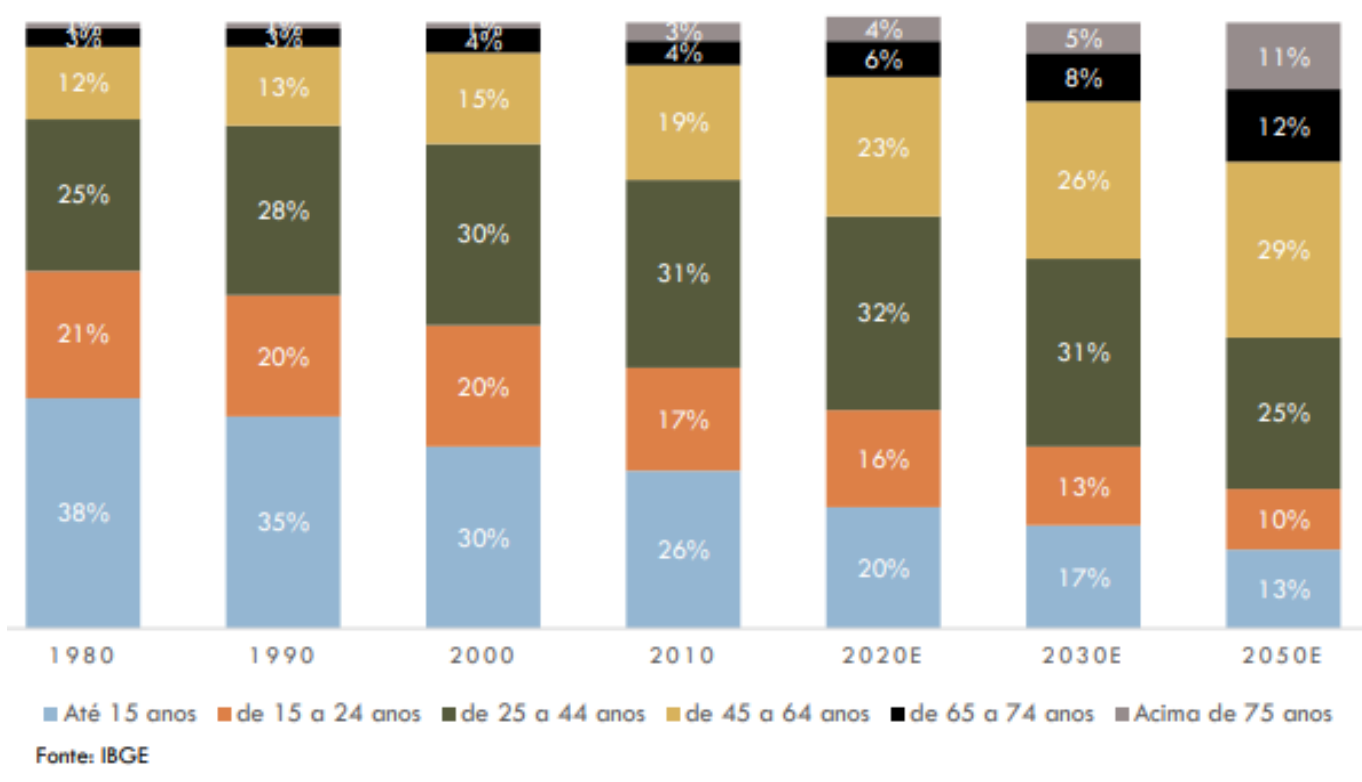

Figura 13 - GRÁFICO DE IDADE POPULAÇÃO - BRASIL

Assim, nas últimas décadas, além do envelhecimento, foi possível observar no Brasil uma mudança de hábitos da população, seja pelo incremento da renda das famílias, seja pelo acesso a novas tecnologias. Entre as mudanças de hábitos, podemos listar:

- $46 \%$ da população brasileira não possui uma vida ativa no ponto de vista de atividades físicas;

- $30 \%$ assistem a mais de 3 horas de televisão, e;

- $15 \%$ da população se declaram fumante.

O resultado disso pode ser visto em índices apresentados por este mesmo instituto, como por exemplo: 
- $21,4 \%$ da população brasileira sofrem de pressão alta;

- $18,5 \%$ possuem problemas de coluna;

- $12,5 \%$ possuem altos níveis de colesterol.

Conforme gráfico abaixo, o sistema de saúde brasileiro é uma indústria que movimenta aproximadamente $R \$ 600$ bilhões, e em franca expansão:

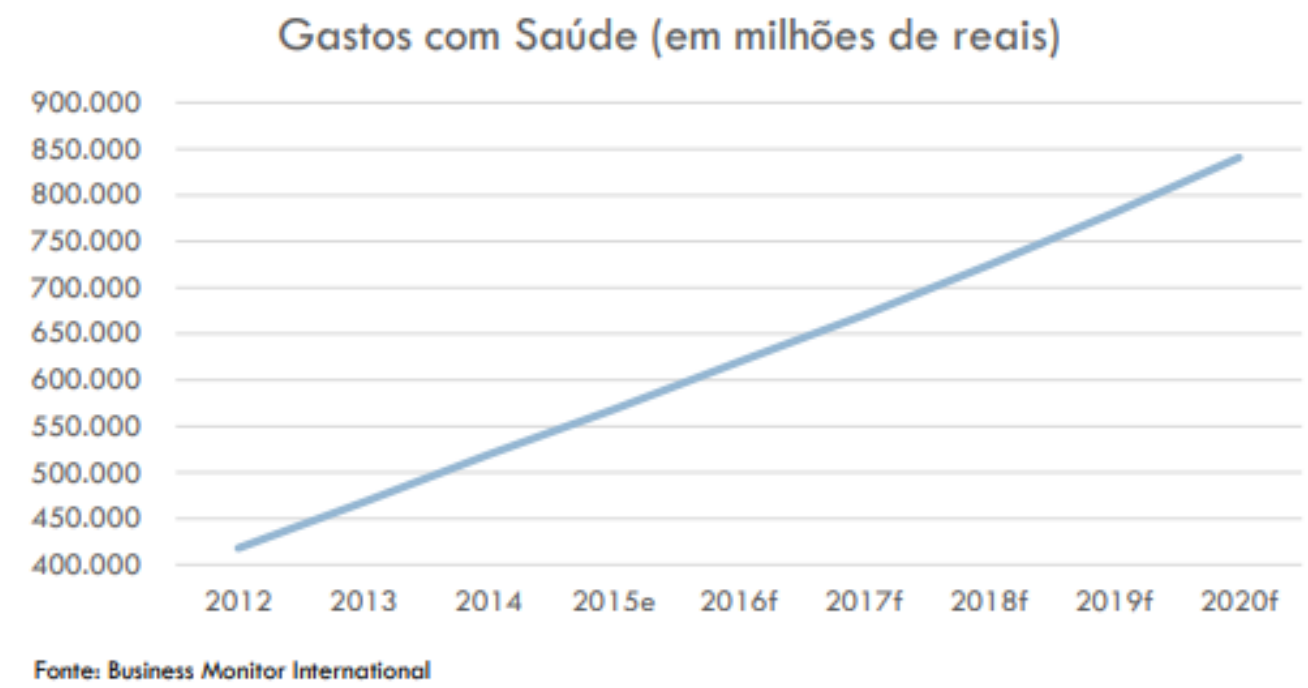

Figura 14 - GASTOS SAÚDE - BRASIL

O sistema de saúde brasileiro é dividido entre o sistema público centralizado pelo Sistema Único de Saúde - SUS e o Sistema Privado.

\subsubsection{SUS}

Criado pela lei 8080/90, atendendo a previsão constitucional brasileira de direito universal ao acesso a serviços de saúde, o SUS é uma complexa rede de atendimento à população, financiada e gerenciada de forma paralela, mas com obrigações diversas pelos governos federais, estaduais e municipais.

Apesar dos visíveis avanços desde a sua criação, a gestão descentralizada e ineficiente aliada a um investimento baixo per capita (apesar de o custo em relação ao PIB ser comparável ao dos países da OCDE) e discrepâncias regionais acarreta em um sistema com baixos índices de qualidade que ainda não consegue atender a população em sua plenitude.

Apesar de seus problemas estruturais, pesquisas mostram que aproximadamente $80 \%$ da população utiliza algum tipo de serviço oferecido pelo SUS ao longo do ano.

Abaixo é apresentado um gráfico com os gastos governamentais no setor de saúde, assim como uma projeção até 2020 destes gastos: 


\section{Gastos Governamentais com Saúde (mm de reais)}

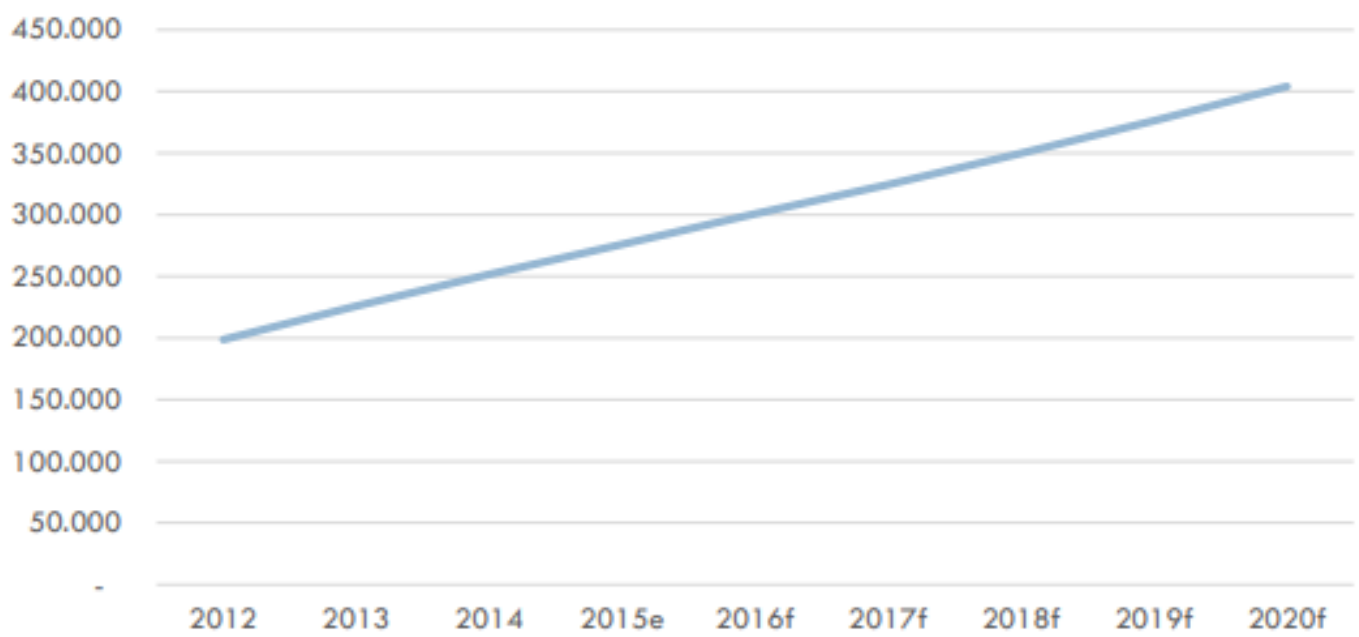

Fonte: Business Monitor International

Figura 15 - GASTOS GOVERNAMENTAIS COM SAÚDE - BRASIL

\subsubsection{O Sistema Privado de Saúde}

Os ganhos de renda da população nas últimas décadas aliado a uma diminuição da concentração somada à ineficiência do sistema público de saúde foram fatores chaves para a existência de um pujante setor privado de saúde, cujos gastos provados podem ser observados no gráfico abaixo:

Gastos Privados com Saúde ( $\mathrm{mm}$ de reais)

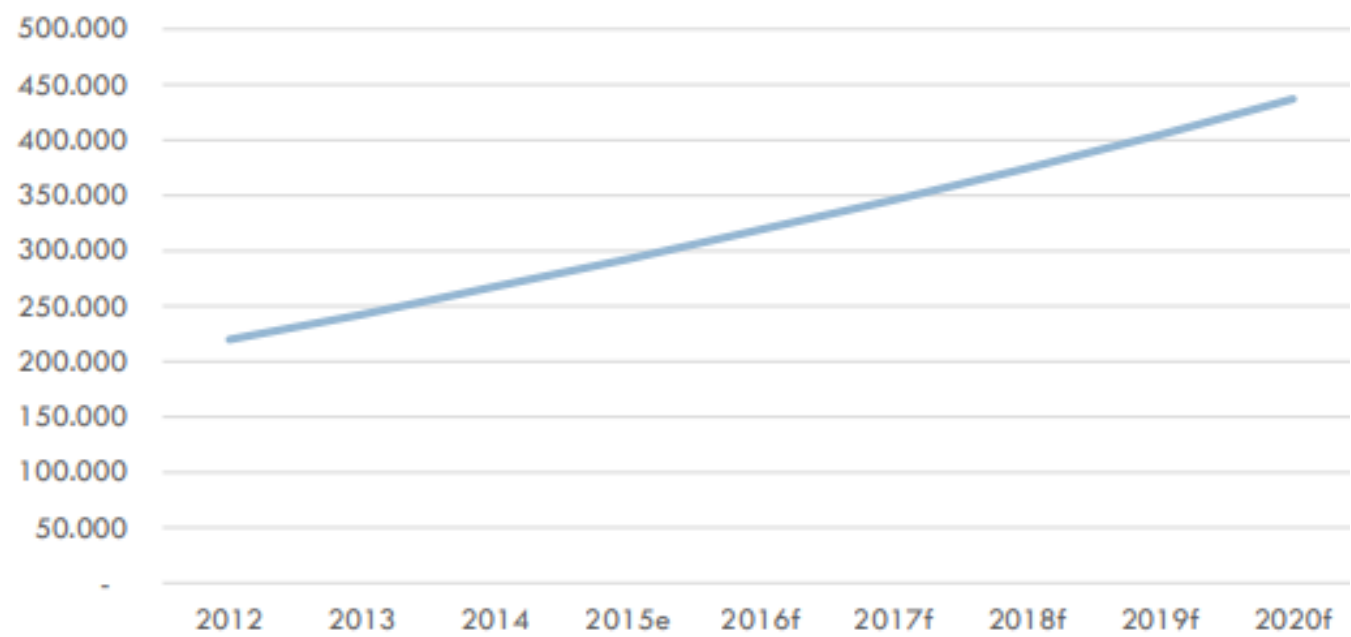

Fonte: Business Monitor International

\section{Figura 16 - GASTOS SISTEMA PRIVADO DE SAÚDE - BRASIL}

Dos valores acima citados, é importante ressaltar a importância dos planos de saúde um mercado que chegou a aproximadamente $R \$ 130$ bilhões em 2014 
e que injetou $R \$ 104$ bilhões em pagamentos para toda a cadeia privada de fornecedores/prestadores de serviço. Deste valor aproximadamente $R \$ 16,5$ bilhões foram gastos em exames médicos.

De acordo com a penetração dos planos de saúde privados na população brasileira subiu de $18,6 \%$ para $25,9 \%$ da população entre 2004 e 2015 . E ainda existe um espaço para uma penetração muito maior uma vez que:

1- A penetração brasileira ainda é pequena se comparada a de países com sistemas de saúde universal como Austrália e Canadá (e com níveis de qualidade de atendimento consideravelmente maiores), e;

2- De acordo com pesquisa divulgada pelo IBOPE, a aquisição de plano de saúde privado é o terceiro produto mais desejado pela população brasileira, atrás apenas de Educação e Imóvel Próprio.

3- Ainda de acordo com a pesquisa IBOPE, dos cerca de 74 pontos percentuais da população que não possuem plano de saúde, 55 pontos percentuais gostariam de ter.

\subsection{O Mercado de POINT-OF-CARE (POC)}

Apesar de ainda incipiente do sistema de saúde brasileiro, a cadeira de diagnósticos Point of Care vem apresentando robusto crescimento no mundo, em especial nos países desenvolvidos, como uma alternativa eficiente aos métodos tradicionais de exames.

De acordo com relatório da empresa norte-americana Grand View Research, Inc., o Mercado de diagnósticos Point of Care (POC) alcançou, em 2018, um total de 18,09 bilhões de dólares, e a expectativa para os próximos anos é de um CAGR de 3,3\% chegando a 21,98 bilhões de dólares em 2025. Os crescentes e constantes investimentos em estudo e progresso entre os players no segmento, com propósito de firmar novos testes e dispositivos para favorecer a determinação e controle de doenças, serão a essência para este aumento. 
U.K. point of care diagnostics/testing market size, by product, 2014 - 2025 (\$ Million)

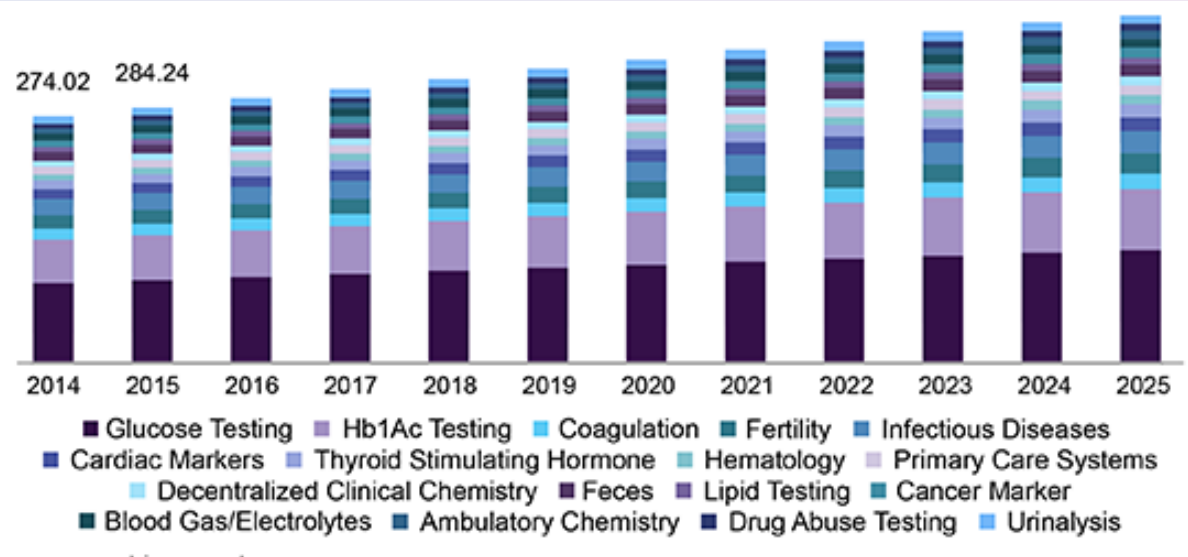

Source: www.grandviewresearch.com

\section{Figura 17 - TAMANHO DE MERCADO POC TEST}

Ademais, a implantação de iniciativas favoráveis de normatização, a fim de produzir progresso e amparo a produção de testes POC, deverá da mesma forma ampliar o desenvolvimento nos próximos anos.

Global point of care diagnostics/testing market share, by end use, 2018 (\%)

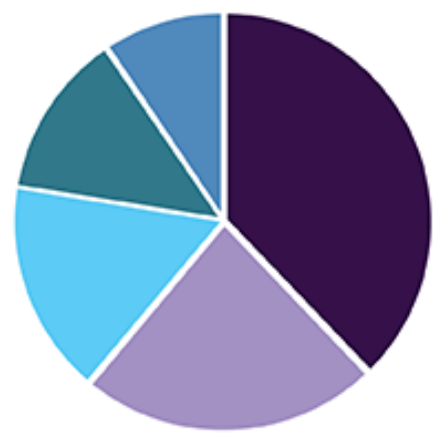

- Clinics

n Hospitals

n' Home

n Assisted Living Healthcare Facilities

n Laboratory

Source: www.grandviewresearch.com

\section{Figura 18 - TAMANHO DO MERCADO DE POC - PRINCIPAIS SETORES}

Ainda segundo o relatório da Grand View Research, Inc. os maiores mercados para esse setor são os Estados Unidos seguidos pela União Europeia, mas os mercados emergentes, em especial Brasil e China possuem um enorme potencial de crescimento para essa indústria uma vez que apresentam um conjunto de fatores como: (i) Iniciativas de Crescimento dos players do setor; (ii) Crescimento na Base de Potenciais Clientes; e (iii) Iniciativas de parcerias e joint ventures entre empresas locais e multinacionais/órgãos de pesquisa. 
Entre os fatores de atratividade deste tipo de diagnostico possível citar, entre outras características:

Resultados Imediatos

$\square$ Baixo Custo

$\square$ Menores amostras, diminuindo o desconforto do paciente.

$\neg$ Fácil manejo e transporte para áreas isoladas/desastres

Testes para doenças infecciosas possuem alta participação desse segmento de relevância expressiva nas atividades de manufatura de testes POC. Ele engloba o diagnóstico rápido para um quantidade significativa de doenças negligenciadas, tais como, HIV, HBV, RSV, VíRUS DO PAPILOMA HUMANO, influenza, HCV, MRSA, TB/dr-TB, HSV, entre outros. Por causa da progressiva incidência de casos relacionados a uma série de doenças infecciosas, iniciativas têm sido tomadas por diversos governos para efetivar e incentivar o diagnóstico prematuro e a triagem, tal como o progresso no desenvolvimento de testes rápidos capazes de marcar entre um porção grande de patógenos, têm sido observadas. Essa existência precisa ser similarmente encarregado pelo desenvolvimento da pleito desse exclusivo nicho de mercado. 


\section{Análise da situação e proposta de solução}

\subsection{A XxxxxxXxxx COMÉRCIO E INDÚSTRIA LTDA}

A XxxxxxXxxx, empresa de pequeno porte de direito privado atualmente no modelo tributário de lucro real, fica sediada no Município do Rio de Janeiro, Estado do Rio de Janeiro, foi criada em 2010 para atuar no mercado focada em diagnósticos Point of Care para facilitar o acesso da população à saúde, através de ferramentas rápidas, precisas e modernas.

A $X x x x x x X x x x$ possui colaborações de institutos nacionais e internacionais e dos governos de vários países do mundo, para que as suas soluções diagnósticas possam melhorar a condição de vida de milhões de pessoas. Abaixo são apresentados os diagnósticos que compõem o Mix de produtos da $X x x x x x X x x x$ :

- DENGUE IgG IGM

- DENGUE Ag NS1

- TROPONINA

- HBsAG

- HCV

- CHIKUNGUNYA - CAMPO

- HIV $1 / 2$

- tRIO CARDIO

- CHIKUNGUNYA IgM

- COMBO DENGUE IgG/IgM NS1

- COMBO TOXO IGgGM

- SIFILIS

- MALARIA

- HANSENIASE

- OVULARE

- GRAVILEX

- DENGUE Ag NS1 - CAMPO

- DENGUE IgG IGM - CAMPO
- COMBO DENGUE IGgGM CHIKUNGUNYA

- COMBO DENGUE NS1 CHIKUNGUNYA

- CAMPO COMBO DENGUE IGgGM CHIKUNGUNYA

- CAMPO COMBO DENGUE NS1 CHIKUNGUNYA

- ACTION

- ZIKA IgG + IgM

- ZIKA NS1

- CHIKUNGUNYA IgG/lgM

- OL INFLUENZA A/B 
A sede da $X x x x x x X x x x$, tanto administrativa como de produção, fica localizada $x x x x x x x x x x x x x x x x x x x x x x x x x x x x x x x x$ Rio de Janeiro, com fácil acesso a vias estratégicas como a Avenida Brasil e BR-101.

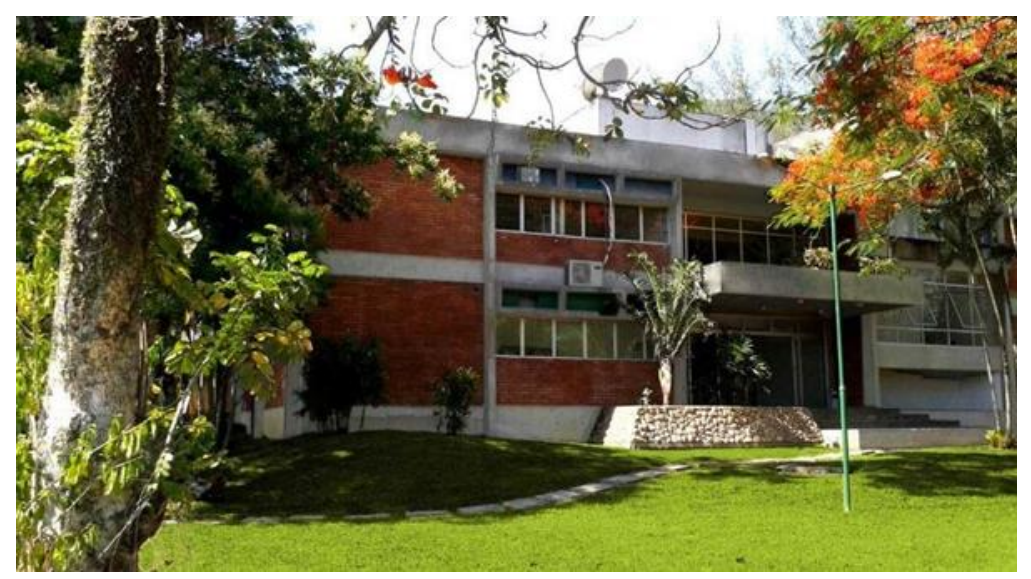

Figura 19 - ACERVO DA COMPANHIA

\section{LOCALIZAÇÃO}

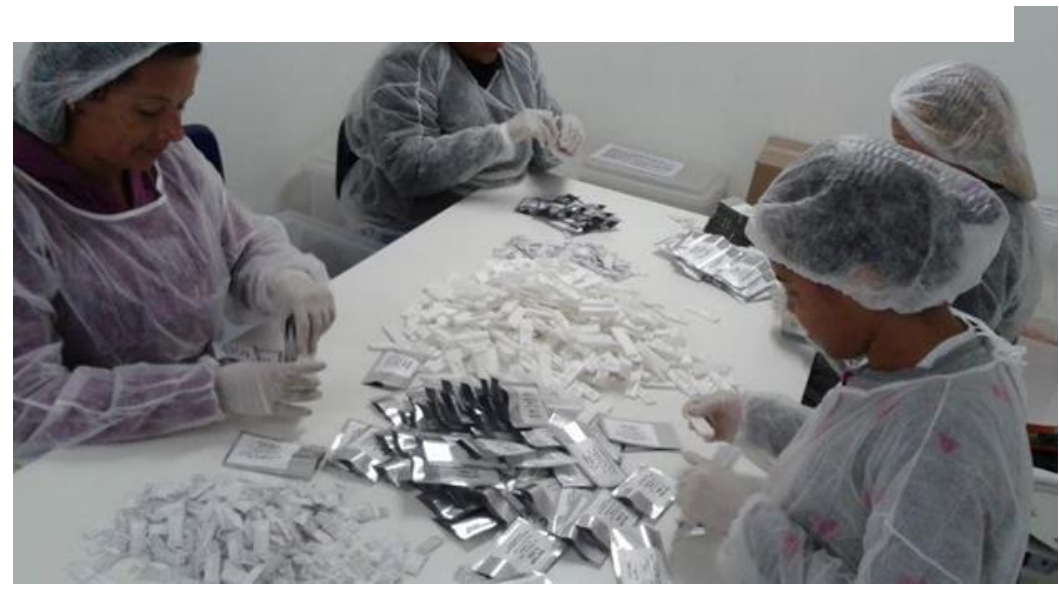

Figura 20 - ACERVO DA COMPANHIA PRODUÇÃO

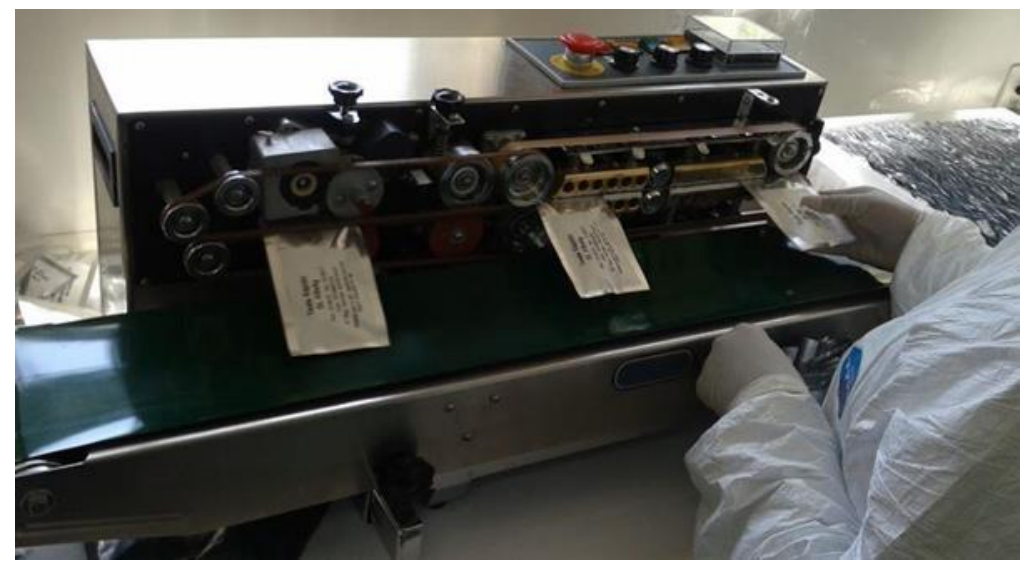

Figura 21 - ACERVO DA COMPANHIA SELAGEM DE PRODUTOS 
O processo tradicionalmente vigente no mercado brasileiro para de diagnóstico de pacientes segue o processo abaixo:

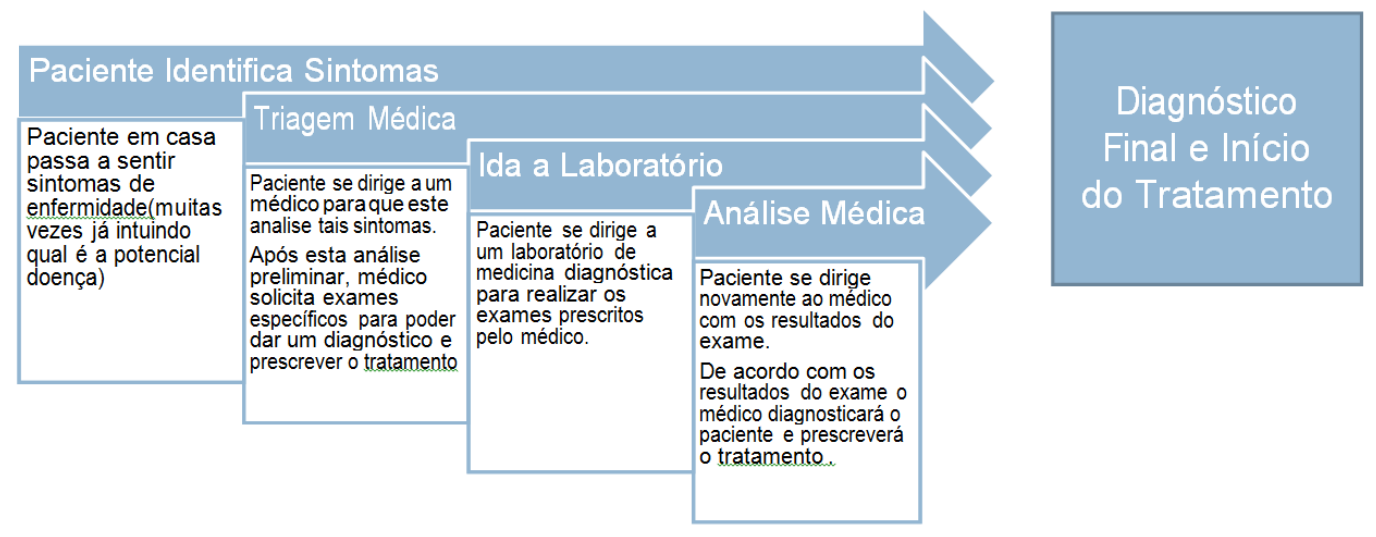

Figura 22 - ACERVO DA COMPANHIA TRIAGEM CONVENCIONAL

Em casos de municípios com boa estrutura hospitalar e em especial para pacientes atendidos pela rede privada, esse processo acaba sendo rápido, porém essa é uma realidade muito restrita considerando a atual conjuntura do mercado de saúde brasileiro.

Nos casos de muitos pacientes, em especial os atendidos pelo SUS e de municípios menores, o processo até o diagnóstico final demora dias, com necessidade de deslocamentos para cada uma das etapas acima, o que torna 0 fluxo acima apresentado moroso e cansativo.

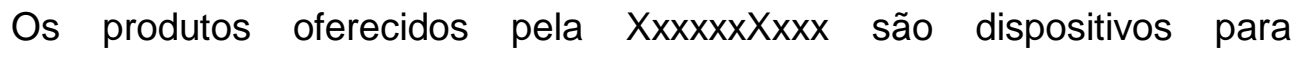
diagnósticos Point of Care, no qual os pacientes não dependem dos serviços das redes de medicina diagnóstica para obter diagnósticos a respeito de sua condição de saúde. 
Desta forma os dispositivos oferecidos pela $X x x x x x X x x x$, quando usados pelos médicos, possibilitam o diagnóstico e prescrição do tratamento já na primeira visita. $\cdot$

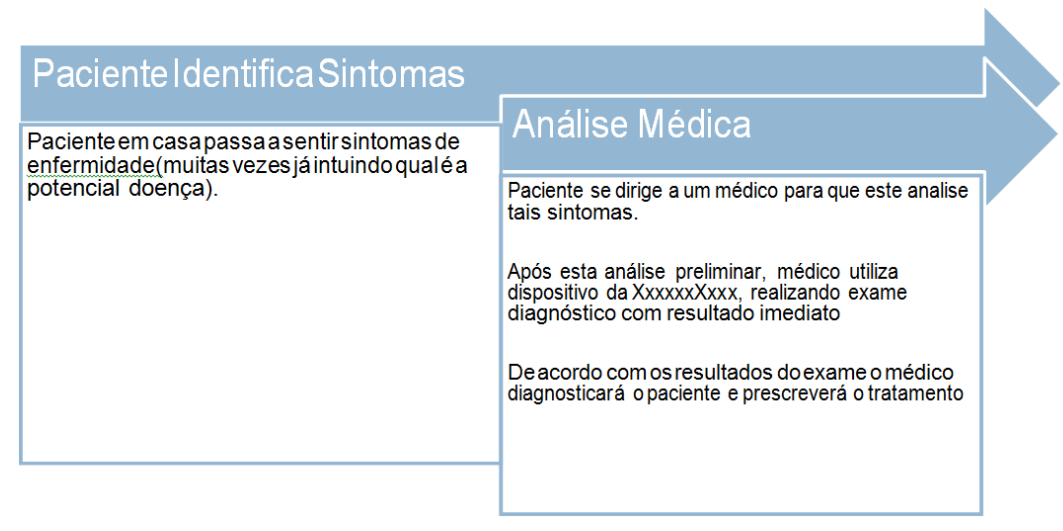

Figura 23 - ACERVO DA COMPANHIA NOVA TRIAGEM ATRAVÉS DO USO DOS TESTES DE DIAGNÓSTICO RÁPIDO

Os processos anteriormente apresentados consideram que:

1- Os sintomas sentidos pelo paciente representam efetivamente uma doença;

2- O paciente conseguiu agendar atendimento médico em um tempo que atenda a sua necessidade/expectativa;

3- O deslocamento para o médico não representa grande esforço, e;

4- O paciente está disposto a se expor a consultas/exames (existem diversos casos no qual os pacientes não querem se expor, como por exemplo, diagnósticos de DSTs).

Assim, como base no exposto acima, podemos ver que, o potencial de valoração da companhia em questão e bastante alto.

Tendo em vista a característica dos dispositivos oferecidos pela XxxxxxXxxx, o mercado consumidor dos dispositivos da XxxxxxXxxx é dividido em:

B2B Saúde: Venda diretamente a empresas do setor de saúde como, por exemplo, Hospitais, clinicas e laboratórios que buscam alternativas rápidas e baratas para diagnostico de seus pacientes. Além disso, é possível afirmar que potencialmente planos de saúde podem vir a ser clientes em especial do Blackbox, visando diminuir o número de visitas a hospitais próprios ou conveniados para realização de exames diagnósticos.

B2B Outros: Venda direta para empresas que exploram áreas com pouca ou nenhuma estrutura de saúde como, por exemplo, grandes obras de 
infraestrutura em locais isolados e plataformas de exploração e produção de óleo e gás.

B2C: Venda direta a médicos ou pacientes por meio de representantes comerciais e venda em farmácias.

B2G: Hospitais e postos de saúde do SUS que não estejam aptos a processar toda a demanda existente para diagnósticos, desejam ter uma alternativa rápida e barata ou simplesmente não tenha tecnologia disponível para realizar determinados testes. Além do SUS, as forças armadas e empresas públicas possuem elevada demanda de produtos semelhante ao demonstrado nos clientes tipo "B2B Outros".

\subsection{Formação de Capital}

Para o presente estudo, conforme detalhado no capítulo 2, as premissas e formação de capital ficou da seguinte maneira:

\begin{tabular}{|c|c|c|}
\hline & Valor & Fonte \\
\hline Taxa Livre de Risco (RF EUA) & $2,12 \%$ & Federal Reserve - 10y Bond - https://fred. stlouisfed. org/series/DGS10/ \\
\hline Risco Brasil EMBI+ & $4,43 \%$ & $\begin{array}{l}\text { JP Morgan + projeção- } \\
\text { http://www.ipeadata.gov.br/ExibeSerie.aspx?serid=40940\&module=M }\end{array}$ \\
\hline Beta Desalavancado & 1,17 & Aswath Damoradan - Unlevered Beta \\
\hline Beta Realavancado & 1,72 & \\
\hline Premio de Risco do Mercado & $7,62 \%$ & \\
\hline Prêmio de Risco Tamanho da Empresa & $19,00 \%$ & $\begin{array}{l}\text { Ibbotson - https://www.duffandphelps.com/- } \\
\text { /media/assets/pdfs/publications/valuation/valuation-insights/valuation- } \\
\text { insights-q1-2019.ashx?la=em }\end{array}$ \\
\hline Ke Real & $38,63 \%$ & Ke Nominal USD \\
\hline Ke Nominal USD & $35,91 \%$ & \\
\hline Divida/(D+E) & $71,05 \%$ & Balanço 2018 Orangelife \\
\hline Equity/(D+E) & $28,95 \%$ & Balanço 2018 Orangelife \\
\hline Carga Tributária Brasil & $33,58 \%$ & $\begin{array}{l}\text { http://agenciabrasil.ebc.com.br/economia/noticia/2019- } \\
\text { 03/carga-tributaria-sobe-em-2018-e-atinge-3358-do-pib-estima- } \\
\text { tesou ro }\end{array}$ \\
\hline Custo da Dívida & $18,50 \%$ & Estimativa - Autor \\
\hline WACC real & $19,13 \%$ & \\
\hline
\end{tabular}

\section{Figura 24 - TRABALHO DO AUTOR FORMAÇÃO DE CAPITAL}

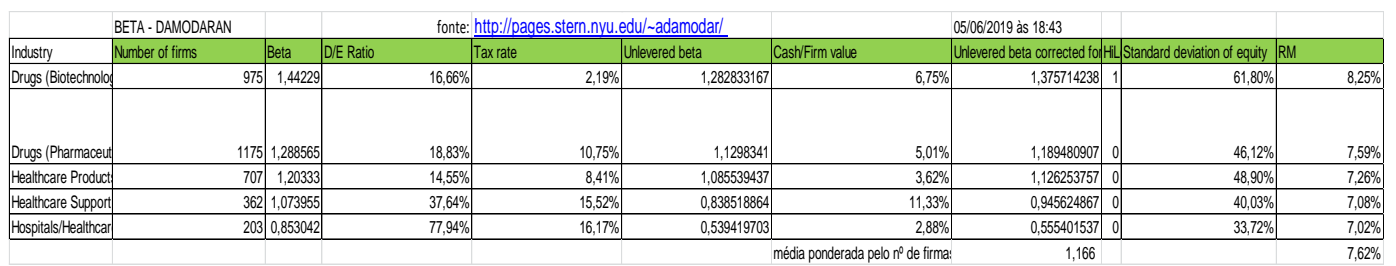

Figura 25 - TRABALHO DO AUTOR BETA DESALAVANCADO E RISCO DE MERCADO

Como métrica para a estrutura de capital de empresas comparáveis foi usada a de empresas do setor de fornecimento de equipamentos/serviços para o 
setor de Healthcare, ponderadas pelo número de firmas. São elas respectivamente:

\begin{tabular}{|l|r|}
\hline Indústria & Número de firmas \\
\hline Drogas (biotecnologia) & 975 \\
\hline & \\
Drogas (Farmacêutica & 1175 \\
\hline Produtos de Saúde & 707 \\
\hline Serviço de suporte de & 362 \\
\hline Hospitais / Fac. De Sa & 203 \\
\hline
\end{tabular}

Figura 26 - DADOS DO SETOR http://pages.stern.nyu.edu/ adamodar/ ; DAMODARAN (2019)

O ponto inicial para estimar o custo do capital próprio é a taxa de retorno livre de risco. Na prática, a taxa de juros de longo prazo de investimentos financeiros livre de risco (e.g. títulos financeiros pré-fixados do setor público) é usada como guia para determinar a taxa de juros de interesse.

O prêmio de risco de mercado é definido como a diferença entre um retorno esperado num portfólio de mercado e a taxa livre de risco. Estudos de mercado de capitais de longo prazo têm mostrado que os investimentos históricos em ações geram retornos entre 7,0\% e 8,0\% mais altos que os investimentos em ativos de baixo risco.

O prêmio de risco médio deve ser modificado para refletir a estrutura de risco específico. O CAPM leva em conta o risco específico da companhia através dos fatores beta. Tais fatores representam uma figura de ponderação para a sensibilidade do retorno da companhia comparada com a tendência de todo o mercado. Eles são, portanto, medidas de volatilidade do risco sistêmico. Quanto maior for a diferença positiva entre o beta e número um, maior será a volatilidade. Quanto maior for a diferença negativa entre o beta e o número um, menor a volatilidade com relação a média do mercado. Fatores betas são idealmente determinados com referência a todo mercado de capitais, desde que o conceito de risco sistêmico e específico exija que ações individuais sejam medidas com relação ao portfólio do mercado.

Ainda dentro das premissas do analise, foram aplicados "Custos Extraordinários" com base em projetos de expansão em andamento e passados pela companhia sendo eles: 


\begin{tabular}{|l|r|}
\hline Televisão & $600.000,00$ \\
\hline Radio & $100.000,00$ \\
\hline Jornal & $80.000,00$ \\
\hline Advogado - Causas Gerais & $18.000,00$ \\
\hline Advogado - Trabalhista & $87.000,00$ \\
\hline Advogado - Marcas/Patente & $98.000,00$ \\
\hline Entrada USA & $139.539,88$ \\
\hline
\end{tabular}

\section{Figura 27 - TRABALHO DO AUTOR “CUSTOS EXTRAORDINÁRIOS”}

\subsubsection{FCFF (Free Cash Flow to the Firm)}

O fluxo de caixa livre da $X x x x x x X x x x$ foi calculado de acordo com as premissas de projeção de resultado e Capital de Giro, bem como os demais parâmetros apresentados a seguir, até o ano de 2023. A projeção anual do fluxo de caixa é apresentada abaixo:

$\underline{\text { Receitas }}$

\begin{tabular}{|c|c|c|c|c|c|}
\hline Receita Bruta & $14.871 .180,00$ & $15.089 .470,43$ & $21.325 .416,00$ & $23.791 .007,52$ & 26.718.939,25 \\
\hline ICMS & $1.784 .541,60$ & $1.810 .736,45-$ & $2.559 .049,92$ & 2.854.920,90 & $3.206 .272,71$ \\
\hline ISS & - & - & - & - & - \\
\hline PIS & $96.662,67$ & $98.081,56-$ & $138.615,20-$ & $154.641,55-$ & $173.673,11$ \\
\hline COFINS & $446.135,40$ & $446.135,40-$ & $446.135,40-$ & $446.135,40$ & $446.135,40$ \\
\hline Receita Líquida & $12.543 .840,33$ & $12.734 .517,02$ & $18.181 .615,48$ & $20.335 .309,67$ & $22.892 .858,03$ \\
\hline Custo de Produção dos Exames & $3.269 .769,44$ & 3.274.135,25 - & 4.752.913,05 - & $5.265 .307,03-$ & $5.866 .902,64$ \\
\hline Custo Administrativos Pré Expansão (Sem RH) & $1.536 .149,14$ & 1.536.149,14 - & 1.536.149,14 - & 1.536.149,14 & 1.536.149,14 \\
\hline Custos RH Pré Expansão & $1.567 .564,17$ & 1.567.564,17 - & $1.567 .564,17$ & $1.567 .564,17$ & $1.567 .564,17$ \\
\hline Custos Administrativos Pós Expansão (Sem RH) & - & $-\quad-$ & $498.237,50$ & $498.237,50$ & $498.237,50$ \\
\hline Custos RH Pós Expansão & - & - & $3.166 .675,51$ & $3.166 .675,51$ & $3.166 .675,51$ \\
\hline Custos Extraordinários expansão & - & $701.587,42-$ & $409.727,06-$ & $11.225,40$ & - \\
\hline EBITDA & $6.170 .357,58$ & $5.655 .081,04$ & $6.250 .349,04$ & $8.290 .150,91$ & $10.257 .329,08$ \\
\hline EBITDA Ajustado (excluindo Custos Extraordinários) & $6.170 .357,58$ & $6.356 .668,46$ & $6.660 .076,10$ & $8.301 .376,31$ & $10.257 .329,08$ \\
\hline Depreciação e Amortização & $128.445,00$ & $128.445,00-$ & $128.445,00-$ & $924.962,00-$ & $917.968,67$ \\
\hline EBIT & $6.041 .912,58$ & 6.228.223,46 & $6.531 .631,10$ & 7.376.414,31 & 9.339.360,41 \\
\hline \multicolumn{6}{|l|}{$\begin{array}{l}\text { Custos Financeiros } \\
\text { Receitas Financeiras }\end{array}$} \\
\hline Lucro Antes dos Impostos & $6.041 .912,58$ & $6.228 .223,46$ & $6.531 .631,10$ & 7.376.414,31 & $9.339 .360,41$ \\
\hline IRPJ & $327.165,96$ & $331.968,35-$ & 469.159,15 & $523.402,17$ & $587.816,66$ \\
\hline CSLL & $160.608,74$ & $162.966,28-$ & $230.314,49$ & $256.942,88$ & $288.564,54$ \\
\hline Lucro Líquido & $5.554 .137,88$ & 5.733.288,83 & 5.832.157,45 & $6.596 .069,26$ & $8.462 .979,20$ \\
\hline
\end{tabular}

Figura 28 - TRABALHO DO AUTOR FLUXO DE CAIXA LIVRE

\subsection{Perpetuidade}

Para o cálculo do valor da perpetuidade, foi considerada uma taxa de crescimento real de $1,0 \%$, ou seja, crescendo $1 \%$ acima da inflação. Foi subtraído da taxa de desconto, o percentual de 1,0\% chegando assim na taxa de 
capitalização $(\mathrm{k}-\mathrm{g})$. A taxa de capitalização foi utilizada para estimar o valor da perpetuidade, com base no modelo de crescimento constante, conforme demonstrado a seguir:

Valor da perpetuidade $=($ Fluxo de caixa livre da perpetuidade $) /(\mathbf{k}-\mathbf{g})$ 


\section{Conclusão - Valuation Pré e Pós Money}

Com base nas informações e projeções minha avaliação indica uma estimativa de valor de $\mathbf{R} \mathbf{3} \mathbf{3 2 . 0 2 6 . 8 9 1 , 0 0}$ (Trinta e dois milhões, vinte e seis mil, oitocentos e noventa e um reais) para $100 \%$ do capital da XxxxxxXxxx pré Money.

Abaixo é apresentada a estrutura societária da XxxxxxXxxx após o aporte de, aproximadamente, $R \$ 30$ milhões de investidores terceiros visando a manutenção do controle majoritário das cotas emitidas pela Administração da companhia:

\begin{tabular}{|c|c|c|c|c|c|c|}
\hline & 2019 & 2020 & 2021 & 2022 & 2023 & Perpetuidade \\
\hline EBIT & $6.041 .912,58$ & $6.228 .223,46$ & $6.531 .631,10$ & $7.376 .414,31$ & $9.339 .360,41$ & - \\
\hline IRPJ + CSLL & $487.774,70$ & $494.934,63$ & $699.473,64$ & $780.345,05-$ & $876.381,21$ & - \\
\hline Depreciação & $128.445,00$ & $128.445,00$ & $128.445,00$ & $924.962,00$ & $917.968,67$ & - \\
\hline Capex & - - & $3.944 .935,00$ & $3.944 .935,00$ & $328.744,58$ & - & - \\
\hline Variação do Capital de Giro & - & $74.213,60$ & $120.314,66$ & $195.497,19-$ & $232.729,64$ & - \\
\hline FC Acionista no Período & $5.682 .582,88$ & $1.842 .585,23$ & $1.895 .352,79$ & $6.996 .789,49$ & $9.148 .218,23$ & $50.970 .699,03$ \\
\hline Fluxo de Caixa Descontado & $4.953 .589,36$ & $1.344 .561,64$ & $1.158 .162,95$ & $3.585 .549,54$ & $3.951 .430,96$ & $17.070 .490,47$ \\
\hline
\end{tabular}

Figura 29 - TRABALHO DO AUTOR VALUATION ESPERADO

\begin{tabular}{lr} 
FC Descontado & $15.904 .009,72$ \\
Perpetuidade & $17.070 .490,47$ \\
Dívida Líquida & $947.608,27$ \\
& \\
\hline & \\
Valor das Cotas de Emissão da Orangelife & $32.026 .891,92$ \\
Valor do Aporte dos Investidores & $30.763 .873,45$ \\
Valor das Cotas de Emissão da Orangelife após aportes & $62.790 .765,37$ \\
& \\
\hline \% das Cotas em poder do Fundador Após Aporte & $51 \%$ \\
\% das Cotas em poder dos Investidores Após Aporte & $49 \%$
\end{tabular}

Figura 30 - TRABALHO DO AUTOR FLUXO DE CAIXA E ESTIMATIVA DE COTAS 


\section{1.Índice de Solvência de Kanitz (1978)}

\begin{tabular}{|c|c|c|c|c|}
\hline Indicadores & & Efeito & Peso & 2019 \\
\hline Retorno sobre o PL & ROE & + & 0,05 & $103,3 \%$ \\
\hline Liquidez geral & LG & + & 1,65 & 5,90 \\
\hline Liquidez seca & LS & + & 3,55 & 4,40 \\
\hline Liquidez corrente & LC & - & 1,06 & 6,03 \\
\hline Grau de endividament & GE & - & 0,33 & $19,4 \%$ \\
\hline Índice de Kanitz & $Y$ & \multicolumn{2}{|c|}{ TRANQUILO } & 18,95 \\
\hline
\end{tabular}

Figura 31 - TRABALHO DO AUTOR APLICAÇÃO DE KANITZ

Por fim, podemos ver que a empresa e altamente saudável sendo classificada como "tranquilo" no índice de solvência de Kanitz. Vale também destacar que o Cash Firm, que é a variação entre o Valor Projetado/Valor na perpetuidade da empresa, está em $07,33 \%$ o que mostra que os valores da empresa hoje e na perpetuidade são bem equilibrados. 


\section{Referências}

ANDRADE, Maria Margarida. Introdução à metodologia do trabalho científico: elaboração de trabalhos na graduação. 5. ed. São Paulo: Atlas, 2001.

ASSAF NETO, Alexandre. Finanças Corporativas e Valor. 3ª Ed., São Paulo: Atlas, 2008.

ASSAF NETO, Alexandre. Mercado Financeiro. 7ª Ed., São Paulo: Atlas, 2006.

COPELAND, THOMAS E.; KOLLER, T.; MURRIN, J. Valuation: Measuring and Managing the Value of Companies. 2.ed. New York: John Wiley \& Son, Inc., 1996.

DESAI, M.; PINHO, RICARDO R. Drilling South: Petrobras Evaluates Pecom. Harvard Business School, 2004.

DAMODARAN, Aswath. Avaliação de investimentos: Ferramentas e Técnicas para a Determinação do Valor de Qualquer Ativo. Rio de Janeiro: Qualitymark, 1999.

DAMODARAN, Aswath. Finanças Corporativas - Teoria e Prática. $2^{\underline{a}}$ Ed. Porto Alegre. Bookman, 2004

DAMODARAN, Aswath - INVESTMENT VALUATION: SECOND EDITION.

Estados Unidos, John wiley, 1996.

DAMODARAN, Aswath - http://pages.stern.nyu.edu/ adamodar/. 05/06/2019 às $18: 43$

FERREIRA, A. B. de H. Dicionário da língua portuguesa. Rio de Janeiro: Nova Fronteira, 1988.

LEMME, Celso Funcia. Economia \& Conjuntura Análise da Conjuntura Macroeconômica. Março de 2004 - Ano 4 - Número 50.

HELFERT, Erich A. Técnicas de Análise Financeira. Porto Alegre: Bookman, 2000.

PÓVOA, Alexandre. Valuation: Como Precificar Ações. 2ª Ed., São Paulo: Globo, 2007.

Revisão dos modelos de avaliação de empresas e suas aplicações nas práticas de mercado; Celso Funcia Lemme, julho de 2000 - artigos www.maxwell.vrac.puc-rio.br/15022/15022_5.PDF 
ROSS, Stephen A.; JORDAN, Bradford D.; WESTERFIELD, Randolph W.

Administração Financeira - 8aㅡ Ed. Bradford

Técnicas de Analise Financeira - 9a Ed. BOOKMAN COMPANHIA EDITORA LTDA - Erich A. Helfert

KANITZ, Stephen Charles. Como prever falências de empresas. Artigo publicado na Revista Exame, dezembro de 1974

Grand View Research Inc., USA. Point of Care Diagnostics/Testing Market Size, Share \& Trends Analysis Report by Product (Glucose, Blood Gas/Electrolytes, Cancer Marker), By End Use (Clinic, Hospital), And Segment Forecasts, 2019 2025. Grand View Research Inc., USA 10 de março de 2019 disponível em <https://www.grandviewresearch.com/industry-analysis/point-of-care-pocdiagnostics-industry>. Acessado em: 20 de maio de 2019. 